\title{
Remplacement du tourteau de soja par de la farine de viande et des associations de protéagineux dans l'alimentation du poulet de chair
}

\author{
M. LARBIER et J.C. BLUM \\ I.N.R.A., Station de Recherches avicoles, \\ Centre de Recherches de Tours, \\ Nouzilly, F 37380 Monnaie
}

\begin{abstract}
Résumé
1080 poulets de chair de sexe mâle sont élevés jusqu'à l'âge de 7 semaines et répartis en 9 lots. Le lot témoin reçoit un aliment de démarrage TD (tableau 2) (de 0 à 4 semaines), puis un aliment de finition TF (de 4 à 7 semaines) (tableau 3) de type maïs-blé-tourteau de soja. Quatre lots sont nourris depuis la naissance avec des régimes dans lesquels le tourteau de soja est remplacé par de la farine de viande et une association par trois parmi quatre protéagineux : lupin (Lupinus albus L.), féverole (Vicia faba L.), pois (Pisum Sativum L.) et un concentré protéique de luzerne $\left(P X_{1}\right)$. Enfin, quatre lots reçoivent pendant la période de démarrage l'aliment TD, puis l'un des aliments de finition renfermant une association de protéagineux. Les régimes expérimentaux ont les mêmes teneurs en énergie métabolisable et en acides aminés indispensables que les régimes témoins correspondants.

Les performances de croissance dépendent de la nature des protéagineux utilisés et de l'âge à partir duquel les régimes expérimentaux sont distribués. Le remplacement du tourteau de soja par les protéagineux à la fois dans les aliments de démarrage et de finition entraîne une baisse du gain de poids et de l'efficacité alimentaire. En revanche, l'utilisation, limitée à la période de finition, des associations lupin-féverole-pois ou lupin féverole-PX $\mathbf{X}_{1}$ n'affecte pas significativement les performances de croissance. Cependant la présence simultanée de pois et de $\mathrm{PX}_{1}$ diminue toujours le gain de poids et augmente l'indice de consommation.
\end{abstract}

\section{1. - Introduction}

L'alimentation des volailles en France nécessite actuellement l'utilisation annuelle de plus d'un million de tonnes de tourteau de soja. Cette matière première devenue progressivement indispensable est entièrement importée. Aussi est-il nécessaire d'envisager la production nationale de sources de protéines de remplacement. A cet effet, le lupin (Lupinus albus L.), la féverole (Vicia faba L.) et le pois (Pisum sativum L.) sont parmi les protéagineux dont la culture à grande échelle peut être envisagée. Leur valeur nutritionnelle chez les volailles a fait l'objet de travaux nombreux et récents (Vogt, Harnisch \& Krieg, 1979 a et b; Davidson, 1980 ; GuilLAUME, 1980 ; LARBIER, 1980 a et b). La luzerne pourrait constituer elle aussi une source de protéines très intéressante (forte teneur en tryptophane), si ses protéines n'étaient pas diluées par la cellulose. Ses concentrats riches en matières azotées et en 
xanthophylles ont été commercialisés, tel le $\mathrm{PX}_{1}$ obtenu par précipitation des protéines du jus de luzerne (Truchetto, 1977). Utilisé à des taux inférieurs à 5 p. 100 , le $\mathrm{PX}_{1}$ assure d'excellentes performances de croissance (BLUM, 1980).

Qu'il s'agisse de lupin, de féverole, de pois ou de $\mathrm{PX}_{1}$, toutes les études réalisées montrent que chacune de ces matières premières considérée séparément peut remplacer partiellement le tourteau de soja dans l'aliment du poulet de chair sans affecter ni le gain de poids, ni l'efficacité alimentaire.

Dans cette expérience, nous avons envisagé le remplacement total du tourteau de soja non par une seule matière première, mais par une combinaison de trois parmi les quatre protéagineux, associée à de la farine de viande et équilibrée en acides aminés essentiels. De cette façon, chaque protéagineux se trouve incorporé à un taux relativement faible : 10 ou $15 \mathrm{p}$. cent pour le lupin, la féverole et le pois, $5 \mathrm{p} .100$ pour le $\mathrm{PX}_{1}$. La valeur nutritionnelle de telles associations est étudiée en comparant les performances de croissance à la fin des périodes de démarrage et de finition à celles obtenues avec des aliments de formulation courante de type : maïs-blé-tourteau de soja.

\section{2. - Matériel et méthodes}

1080 poussins mâles issus d'un croisement commercial de type chair (JV 15, I.S.A., France) sont élevés au sol, répartis dans 18 cases de $6 \mathrm{~m}^{2}$ chacune et soumis à un éclairement artificiel de 22 heures de lumière par nycthémère.

Pendant les quatre premières semaines de vie, les poussins reçoivent ad libitum l'un des cinq régimes de démarrage, dont la composition est rapportée au tableau 2. L'aliment témoin (maïs-blé-tourteau de soja) est formulé pour répondre à toutes les exigences du poulet de chair. Les régimes expérimentatix présentent les mêmes caractéristiques nutritionnelles déterminées par analyse (3150 à $3170 \mathrm{kcal}$ d'énergie métabolisable/ $\mathrm{kg} ; 20,1$ à 20,3 p. cent de matières azotées; 1,1 p. cent de lysine, 0,80 à 0,84 p. cent d'acides aminés soufrés ; 0,20 à 0,23 p. cent de tryptophane). La composition analytique des protéagineux utilisés figure au tableau 1. Il s'agit du lupin blanc doux «Kalina» (íupinus aïuss $\bar{L}$.), de la féverole à fleur blanche sans tanin "Bianka 》(Vicia faba L.), du pois lisse jaune «Amino» (Pisum sativum. L.) et du concentré protéique de luzerne $\mathrm{PX}_{1}\left({ }^{*}\right)$. Ces protéagineux sont associés par 3 à de la farine de viande. Les taux d'incorporation correspondent aux apports trouvés acceptables au cours d'essais précédents : 9 et $14 \mathrm{p}$. cent de farine de viande, $5 \mathrm{p}$. cent de $\mathbf{P X}_{1}$, 10 à 15 p. cent des autres protéagineux. On distribue le régime témoin de démarrage à 600 poussins ( 10 cases), tandis que chacun des régimes expérimentaux est consommé par 120 poussins ( 2 cases).

Du $29^{\prime \prime}$ au $56^{\circ}$ jour, les poulets reçoivent des régimes de finition constitués selon le même schéma que les régimes démarrage (tableau 3). Ils présentent une valeur comprise entre 3180 et $3190 \mathrm{kcal}$ en énergie métabolisable par $\mathrm{kg}$ et entre 18,4 et 18,7 p. cent en matières azotées totales $(N \times 6,25)$. Leurs teneurs en lysine, acides aminés soufrés et tryptophane, égales respectivement à $0,95-0,75$ et 0,18 p. cent

(*) Le $\mathrm{PX}_{1}$ nous a été fourni par la Société France-Luzerne. 
couvrent largement les besoins (LARBIER \& Dupont, 1980). Parmi les 600 animaux qui avaient été nourris avec le régime témoin de démarrage TD, 120 (2 cases) reçoivent un régime témoin de finition $T F$, à base de maïs, blé et tourteau de soja. Les 480 animaux restants sont répartis en quatre lots et nourris avec l'un des quatre régimes expérimentaux renfermant de la farine de viande et une combinaison de trois protéagineux. En outre, chacun des régimes expérimentaux de finition est distribué aux 120 animaux ayant consommé pendant les quatre premières semaines un aliment renfermant la même combinaison de protéagineux. Tous les aliments sont présentés en granulés de $2,5 \mathrm{~mm}$ de diamètre.

TABleau 1

Caractéristiques analytiques des protéagineux utilisés

Analytical characteristics of the protein plants used

\begin{tabular}{|c|c|c|c|c|c|}
\hline & $\begin{array}{l}\text { Tourteau } \\
\text { de soja } \\
\text { Soybean } \\
\text { Meal }\end{array}$ & $\begin{array}{c}\text { Lupin } \\
\text { « Kalina » } \\
\text { Lupin Seed }\end{array}$ & $\begin{array}{c}\text { Féverole } \\
\text { «Bianca » } \\
\text { Field Bean }\end{array}$ & $\begin{array}{l}\text { Pois } \\
\text { «Amino » } \\
\text { Pea }\end{array}$ & $\begin{array}{c}\mathrm{PX}_{1} \\
\text { Lucerne } \\
\text { Protein } \\
\text { concentrate }\end{array}$ \\
\hline $\begin{array}{l}\text { Energie métabolisable } \\
\quad(\mathrm{Kcal} / \mathrm{kg}) \ldots \ldots \\
\text { Metubolisable energy }\end{array}$ & 2480 & 2480 & 2700 & 2500 & 2550 \\
\hline $\begin{array}{l}\text { Protéines brutes } \\
(\mathrm{N} \times 6,25 \%) \\
\text { Crude protcin }\end{array}$ & 47,0 & 37,9 & 28,0 & 23,4 & 48,3 \\
\hline Lysine $(\%) \ldots \ldots$ & 2,93 & 1,73 & 1,72 & 1,59 & 2,96 \\
\hline Méthionine $(\%) \ldots$ & 0,64 & 0,28 & 0,20 & 0,20 & 1,02 \\
\hline Tryptophane $(\%)$ & 0,63 & 0,26 & 0,25 & 0,20 & 1,16 \\
\hline
\end{tabular}

Le dispositif expérimental ainsi défini comporte trois groupes d'animaux. Le lot témoin consomme pendant toute la durée de l'essai une succession de deux régimes classiques de type maïs-blé-tourteau de soja. Les animaux du deuxième groupe reçoivent depuis la naissance des aliments renfermant de la farine de viande et une combinaison de trois protéagineux. Enfin, le troisième groupe est nourri pendant les quatre premières semaines avec le régime témoin de démarrage puis avec les régimes renfermant les protéagineux. 
TABleau 2

Composition des régimes de démarrage (0-28 jours)

Composition of starter diets $(0-28$ days $)$

\begin{tabular}{|c|c|c|c|c|c|}
\hline $\begin{array}{c}\text { Matières premières } \\
(\%) \\
\text { Ingredients }\end{array}$ & $\begin{array}{l}\text { Témoin } \\
\text { Control }\end{array}$ & $\begin{array}{c}\text { Lupin- } \\
\text { féverole } \\
\text { PX }_{1} \\
\text { Lupin-field } \\
\text { bean-lucerne } \\
\text { protein } \\
\text { concentrate }\end{array}$ & $\begin{array}{l}\text { Lupin- } \\
\text { féverole } \\
\text { Pois } \\
\text { Lupin-field } \\
\text { bean-pea }\end{array}$ & $\begin{array}{l}\text { Lupin-pois } \\
\text { PX }_{1} \\
\text { Lupin-pea- } \\
\text { lucerne } \\
\text { protein } \\
\text { concentrate }\end{array}$ & $\begin{array}{l}\text { Févero'e- } \\
\text { pois } \\
\text { PX }_{1} \\
\text { Field-bean- } \\
\text { pea-lucerne } \\
\text { protein } \\
\text { concentrate }\end{array}$ \\
\hline$\underset{\text { Maize }}{\text { Maïs }} \ldots \ldots \ldots \cdots \cdots$ & 50,35 & 23,72 & 23,67 & 23,72 & 23,80 \\
\hline $\begin{array}{l}\text { Blé } \ldots \ldots \ldots \ldots \ldots \\
\text { Wheat }\end{array}$ & 10 & 25,0 & 25,0 & 25,0 & 25,0 \\
\hline $\begin{array}{l}\text { Tourteau de soja ... } \\
\text { Soybean meal }\end{array}$ & 32 & - & - & - & - \\
\hline Lupin $\ldots \ldots \ldots \ldots$ & 一 & 15 & 10 & 15 & - \\
\hline $\begin{array}{l}\text { Féverole } . . . . . . . . \\
\text { Field bean }\end{array}$ & - & 15 & 10 & - & 15 \\
\hline $\begin{array}{l}\mathrm{PX}_{1} \ldots \ldots \ldots \ldots \\
\text { Lucerne protein } \\
\quad \text { concentrate }\end{array}$ & - & 5 & 一 & 5 & 5 \\
\hline $\begin{array}{l}\text { Pois } \ldots \ldots \ldots \ldots \ldots \\
P e a\end{array}$ & 一 & - & 10 & 15 & 10 \\
\hline $\begin{array}{l}\text { Farine de viande } . . . \\
\text { Meat meal }\end{array}$ & 一 & 9 & 14 & 9 & 14 \\
\hline $\begin{array}{l}\text { Huile de maïs } . . . . \\
\text { Maize oil }\end{array}$ & 4 & 6 & 6 & 6 & 6 \\
\hline $\mathrm{NaCl} \ldots \ldots \ldots \ldots$ & 0,3 & 0,3 & 0,3 & 0,3 & 0,3 \\
\hline Carbonate de $\mathrm{Ca} . . .$. & 0,6 & - & - & - & - \\
\hline Phosphate bicalcique . & 2,0 & - & - & - & - \\
\hline $\begin{array}{l}\text { Oligoéiéments }\left({ }^{*}\right) \ldots \\
\text { Trace elements }\end{array}$ & 0,1 & 0,1 & 0,1 & 0,1 & 0,1 \\
\hline Vitamines $(* *) \ldots \ldots$ & 0,5 & 0,5 & 0,5 & 0,5 & 0,5 \\
\hline DL-méthionine $\ldots \ldots$ & 0,15 & 0,25 & 0,25 & 0,25 & 0,20 \\
\hline L-lysine $\mathrm{HCl} \ldots \ldots$. & - & 0,13 & 0,13 & 0,13 & 0,10 \\
\hline L-tryptophane ...... & - & - & 0,05 & - & - \\
\hline
\end{tabular}

(*) Apportant en $\mathrm{mg}$ pour $100 \mathrm{~kg}$ d'aliment : Co : $88-\mathrm{Cu}: 875-\mathrm{I}: 128-\mathrm{Se}: 15-$ $\mathrm{Zn}: 10000-\mathrm{Fe}: 3500-\mathrm{Mn}: 11000$.

(**) Apportant pour $100 \mathrm{~kg}$ d'aliment : Vitamine A : $1000000 \mathrm{UI}$ - Vitamine $\mathrm{D}_{:}: 150000 \mathrm{UI}$ - Vitamine $\mathrm{E}: 1,5 \mathrm{~g}$ - BHT : $12,5 \mathrm{~g}$ - Ménadione : $0,5 \mathrm{~g}$ - Riboflavine : $0,4 \mathrm{~g}$ - Pantothénate de $\mathrm{Ca}: 0,8 \mathrm{~g}$ - Niacine : $2,5 \mathrm{~g}$ - Pyridoxine : $0,1 \mathrm{~g}$ - Vitamine $\mathbf{B}_{12}: 0,8 \mathrm{mg}$ - Acide folique : $0,02 \mathrm{~g}$ - Biotine : $0,01 \mathrm{~g}$ - Chlorure de choline : $50 \mathrm{~g}$. 
Tableau 3

Composition et caractéristiques des régimes de finition (29-56 jours)

Composition of finishing diets (29-56 days)

\begin{tabular}{|c|c|c|c|c|c|}
\hline $\begin{array}{c}\text { Matières premières } \\
(\%) \\
\text { Ingredients }\end{array}$ & $\begin{array}{l}\text { Témoin } \\
\text { Control }\end{array}$ & $\begin{array}{c}\text { Lupin- } \\
\text { féverole } \\
\text { PX }_{1} \\
\text { Lupin-field } \\
\text { bean-lucerne } \\
\text { protein }\end{array}$ & $\begin{array}{l}\text { Lupin- } \\
\text { féverole } \\
\text { pois } \\
\text { Lupin-field } \\
\text { bean-pea }\end{array}$ & $\begin{array}{l}\text { Lupin-pois } \\
\quad \mathrm{PX}_{1} \\
\text { Lupin-pea- } \\
\text { lucerne } \\
\text { protein } \\
\text { concentrate }\end{array}$ & \begin{tabular}{|} 
Féverole-pois \\
$\mathrm{PX}_{1}$ \\
Field bean- \\
pea-lucerne \\
protein \\
concentrate
\end{tabular} \\
\hline Maïs $_{\text {Maize }}^{\text {Ma. }}$ & 55 & 23,19 & 24,60 & 23,16 & 24,78 \\
\hline $\begin{array}{l}\text { Blé } \ldots \ldots \ldots \ldots \ldots \\
\text { Wheat }\end{array}$ & 10 & 30 & 30 & 30 & 30 \\
\hline $\begin{array}{l}\text { Tourteau de soja ... } \\
\text { Soybean meal }\end{array}$ & 27,5 & - & - & - & 一 \\
\hline Lupin $\ldots \ldots \ldots \ldots$ & - & 15 & 10 & 15 & - \\
\hline 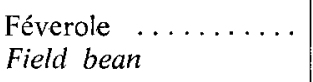 & - & 15 & 10 & 一 & 15 \\
\hline $\begin{array}{l}\mathrm{PX}_{1} \ldots \ldots \ldots \\
\text { Lucerne protein } \\
\quad \text { concentrate }\end{array}$ & - & 5 & - & 5 & 5 \\
\hline $\begin{array}{l}\text { Pois } \ldots \ldots \ldots \ldots \ldots \\
\text { Pea }\end{array}$ & - & 一 & 10 & 15 & 10 \\
\hline $\begin{array}{l}\text { Farine de viande } . . . \\
\text { Meat meal }\end{array}$ & - & 3 & 8 & 3 & 8 \\
\hline $\begin{array}{l}\text { Huile de maïs } . . . . \\
\text { Maize oil }\end{array}$ & 4 & 6 & 6 & 6 & 6 \\
\hline $\mathrm{NaCl} \ldots \ldots \ldots \ldots$ & 0,4 & 0,4 & 0,4 & 0,4 & 0,4 \\
\hline Carbonate de $\mathrm{Ca} . .$. & 0,6 & - & 一 & - & 一 \\
\hline Phosphate bicalcique . & 2,0 & 1,5 & - & 1,5 & - \\
\hline $\begin{array}{l}\text { Oligoéléments }\left({ }^{*}\right) \quad \ldots \\
\text { Trace elements }\end{array}$ & 0,1 & 0,1 & 0,1 & 0,1 & 0,1 \\
\hline Vitamines $(* *) \ldots \ldots$ & 0,5 & 0,5 & 0,5 & 0,5 & 0,5 \\
\hline DL-méthionine $\ldots \ldots$ & 0,12 & 0,21 & 0,22 & 0,21 & 0,16 \\
\hline L-lysine $\mathrm{HCl} \ldots \ldots$ & 一 & 0,10 & 0,13 & 0,13 & 0,06 \\
\hline Tryptophane ....... & - & 一 & 0,05 & - & - \\
\hline
\end{tabular}

(*) Apportant en $\mathrm{mg}$ pour $100 \mathrm{~kg}$ d'aliment : Co : $88-\mathrm{Cu}: 875-\mathrm{I}: 128-\mathrm{Se}: 15$. $\mathrm{Zn}: 10000$ - Fe : $3500-\mathrm{Mn}: 11000$.

(**) Apportant pour $100 \mathrm{~kg}$ d'aliment : Vitamine A : $1000000 \mathrm{UI}$ - Vitamine $\mathrm{D}_{3}: 150000$ UI - Vitamine E : $1,5 \mathrm{~g}$ - BHT : $12,5 \mathrm{~g}$ - Ménadione : $0,5 \mathrm{~g}$ - Riboflavine : 0,4 g Pantothénate de $\mathrm{Ca}: 0,8 \mathrm{~g}$ - Niacine : $2,5 \mathrm{~g}$ - Pyridoxine : $0,1 \mathrm{~g}$ - Vitamine $\mathbf{B}_{12}: 0,8 \mathrm{mg}$ - Acide folique : $0,02 \mathrm{~g}$ - Biotine : 0,01 g-Chlorure de choline : $50 \mathrm{~g}$. 
Tous les animaux sont pesés individuellement à la naissance et aux âges de 4 et 8 semaines après un jeûne total (eau et aliment) de 17 heures, ce qui élimine les variations individuelles dues aux prises alimentaires (Leclerce, Blum \& Boyer, 1977). La consommation alimentaire collective de chaque case est enregistrée pour les deux périodes d'élevage. Les performances de croissance ainsi obtenues permettent de déterminer l'efficacité des associations de protéagineux selon que ces derniers sont consommés par le poulet dès sa naissance ou seulement en période de finition entre 4 et 8 semaines d'âge.

\section{3. - Résultats}

Les animaux nourris avec les régimes témoins maïs-blé-tourteau de soja ont réalisé des performances de croissance tout à fait normales pour le croisement industriel utilisé dans l'expérience. Les poids vifs moyens obtenus sont de 734 et $1979 \mathrm{~g}$ respectivement à 4 et 8 semaines, les indices de consommation de 1,66 et 2,34 pour les deux périodes d'élevage, l'indice cumulé pour la durée totale de l'essai étant de 2,09.

Le remplacement du tourteau de soja par la farine de viande et une combinaison de trois protéagineux a des effets variables selon la nature des matières premières utilisées et l'âge à partir duquel les aliments expérimentaux sont distribués.

Dans les lots d'animaux nourris dès la naissance avec des régimes renfermant des protéagineux, les performances de croissance, comparées à celles obtenues avec les régimes témoins, apparaissent plus ou moins diminuées selon que l'on considère les résultats à 4 ou 8 semaines (tableau 4). A l'âge de quatre semaines, les animaux nourris avec un aliment renfermant du lupin, de la féverole et du $\mathbf{P X}_{1}$ ont réalisé presque les mêmes performances que ceux du lot témoin : ni la consommation alimentaire, ni le poids vif ne sont significativement diminués. En revanche, les autres combinaisons de protéagineux renfermant du pois se sont avérées moins efficaces. En particulier, l'association lupin, pois et $\mathrm{PX}_{1}$ aux taux respectifs de 15,15 et 5 p. cent a entraîné une diminution à la fois de la consommation alimentaire (- 15 p. cent) et du poids vif à 4 semaines (-17 p. cent). Il faut noter que la plus importante diminution de consommation concerne le régime apportant la plus forte proportion de pois.

Les retards de croissance enregistrés pendant les premières semaines se sont accentués au cours de la période de finition. Malgré le maintien de la consommation alimentaire à un niveau égal à celui des animaux du lot témoin, les animaux nourris avec les régimes lupin-féverole- $\mathrm{PX}_{1}$; lupin-féverole-pois et féverole-pois- $\mathrm{PX}_{1}$ ont un poids vif significativement inférieur. Les différences relatives entre animaux expérimentaux et témoins sont respectivement de 7,4,6,4 et 13,4 p. cent par rapport au poids vif des animaux témoins. Dans le lot recevant du lupin, du pois et du $\mathrm{PX}_{1}$ aux taux respectifs de 15,15 et 5 p. cent, les consommations alimentaires sont de 12,9 p. cent plus faibles que dans le lot témoin tandis que le poids vif est diminué de 22,5 p. cent. Enfin, les indices de consommation sont particulièrement élevés (+17 p. cent) avec les deux aliments renfermant à la fois du pois et du $\mathbf{P X}_{1}$.

Dans le tableau 5, nous rapportons les résultats obtenus chez les animaux nourris pendant les quatre premières semaines avec le régime témoin maïs-blé-tour- 


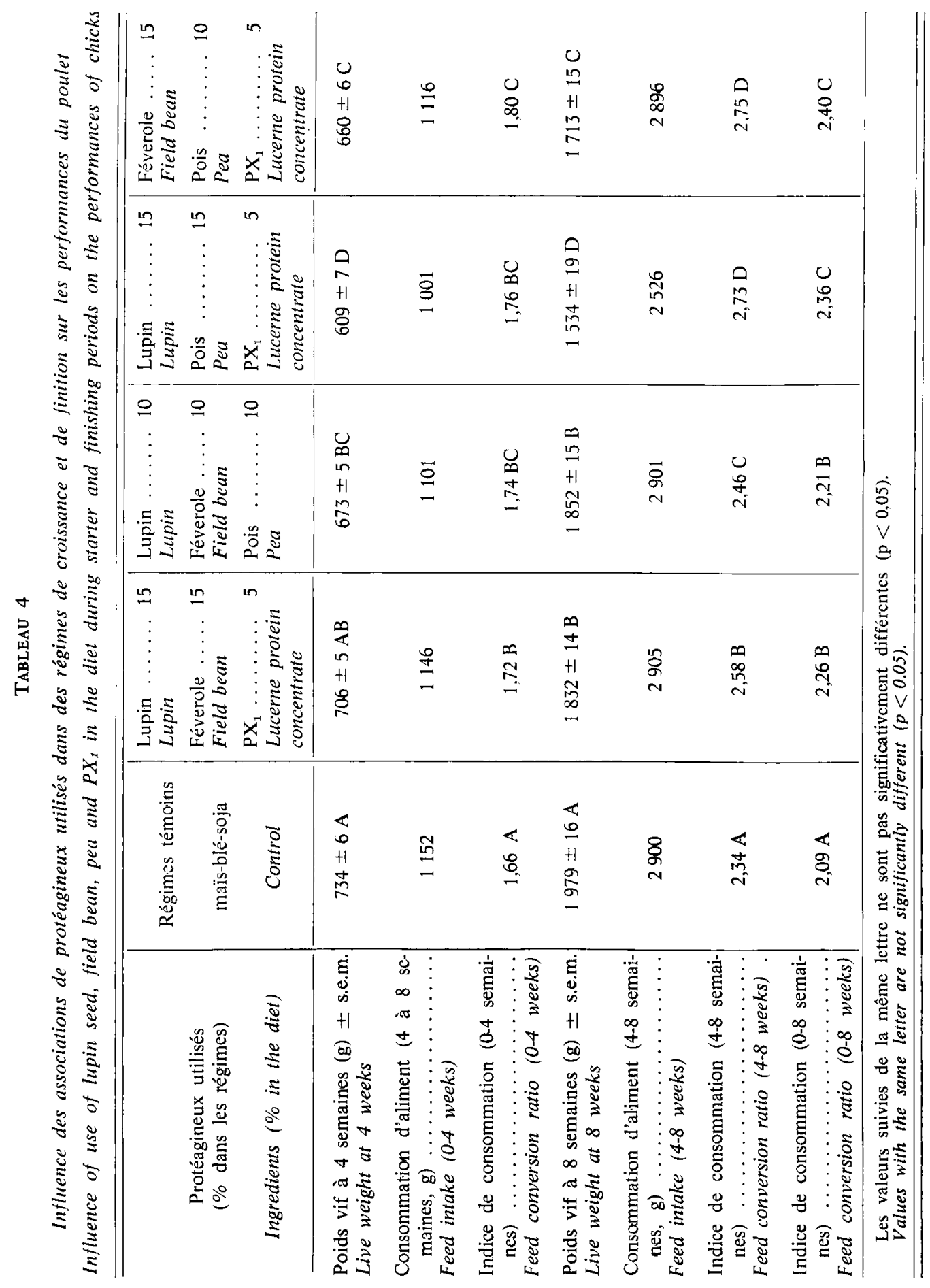




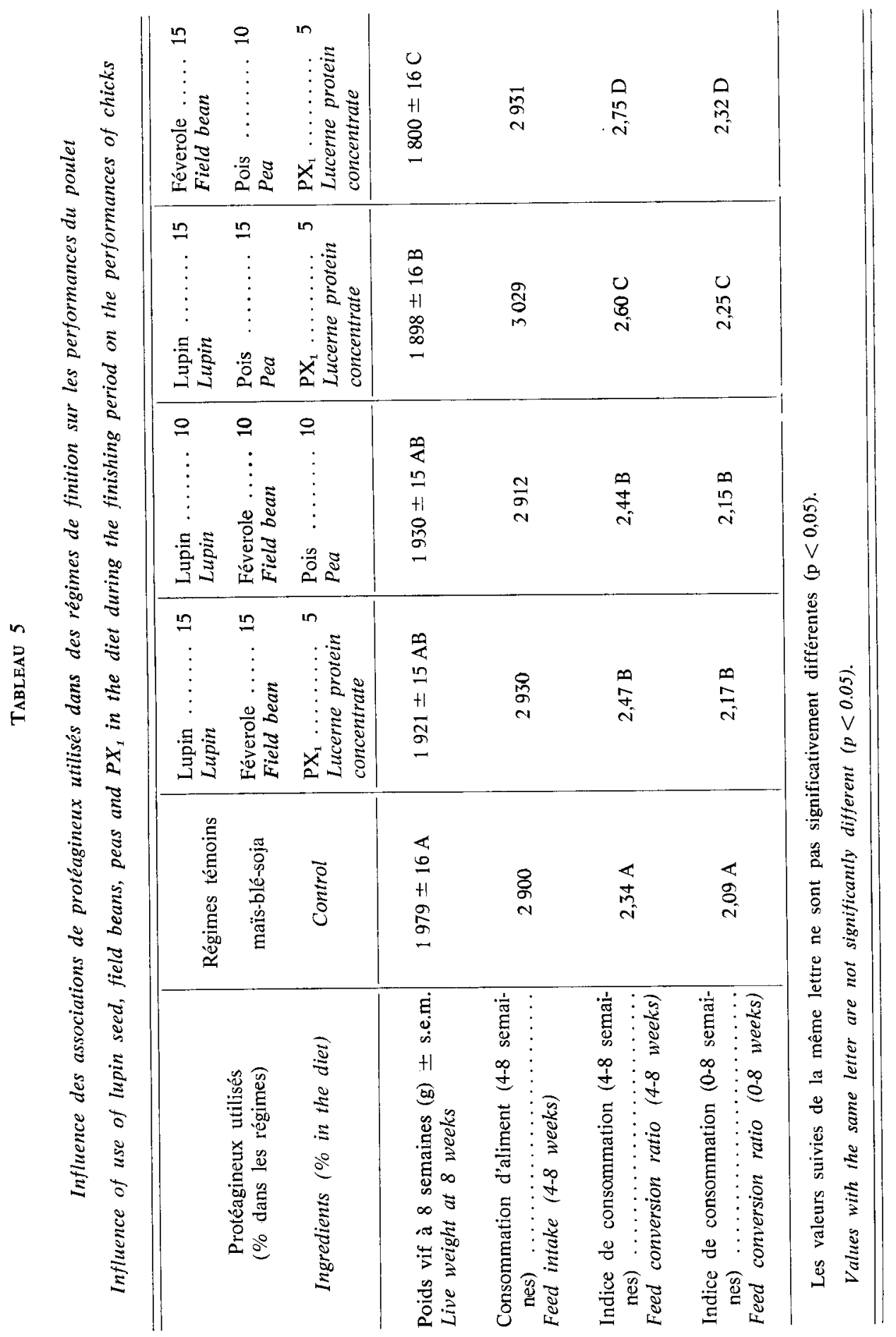


teau de soja puis avec un aliment renfermant l'une des quatre combinaisons de protéagineux. La consommation alimentaire varie peu d'un lot expérimental à l'autre. Les valeurs enregistrées sont très légèrement mais non significativement supérieures à celles observées avec le régime témoin de finition.

En revanche, le poids varie selon la combinaison de protéagineux utilisés. Les animaux nourris avec les régimes comportant les associations lupin-féverole- $\mathbf{P X}_{1}$ et lupin-féverole-pois ont un poids vif qui n'est pas significativement inférieur à celui des animaux témoins. Mais la présence simultanée de pois et de $\mathbf{P X}_{1}$ dans le régime diminue significativement la croissance du poulet. Comparées à l'alimentation témoin, les associations lupin-pois- $\mathrm{PX}_{1}$ et féverole-pois- $\mathrm{PX}_{1}$ conduisent à des poids vifs inférieurs (de 4 et 9 p. cent) et, par voie de conséquence, à des indices de consommation supérieurs (de 11,1 et 17,5 p. cent). Enfin, contrairement aux résultats précédents, l'association féverole-pois- $\mathrm{PX}_{1}$ s'avère moins efficace, tant pour la consommation alimentaire que pour le gain de poids, que l'association lupin-pois$\mathrm{PX}_{1}$.

\section{4. - Discussion}

Les régimes alimentaires utilisés pour chacune des deux périodes d'élevage (croissance et finition) sont isoénergétiques. Pour cela nous avons dû faire varier les taux d'incorporation de céréales et de graisse pour compenser les différences entre les protéagineux. Dans le même temps, nous nous sommes assurés que pour les apports fournis, les valeurs nutritionnelles prises en considération lors de la formulation correspondent bien à celles indiquées dans les tables.

Dans le cas de la farine de viande, nous avons tenu compte de ses caractéristiques analytiques, de telle sorte que même pour l'apport le plus élevé dans cette expérimentation, aucun effet préjudiciable sur les performances de croissance ne puisse être observé.

Les protéagineux utilisés dans cette expérience se trouvent dans les différents régimes alimentaires dans une proportion maximum de $15 \mathrm{p}$. cent sauf pour le concentré protéique de luzerne incorporé au taux unique de 5 p. cent. Ces valeurs sont choisies de telle façon que chaque matière première considérée séparément soit sans effet «antinutritionnel», autrement dit qu'elle puisse assurer des performances maximales lorsque le régime est complet et équilibré. Certes, la limite de tolérance est parfois difficile à définir. Ainsi, dans le cas du $\mathrm{PX}_{1}$, l'étude réalisée antérieurement (BLUM, 1980) montrait que l'apport de 5 p. cent entraînait un léger retard de croissance à 27 jours, ce retard n'étant plus significatif à 49 jours; les concentrations plus fortes (10 ou $15 \mathrm{p}$. cent) étaient en revanche toujours préjudiciables.

Dans le cas des autres protéagineux : lupin, féverole et pois, l'étude de leur valeur nutritionnelle et la détermination de la limite maximum de leur utilisation chez le poulet, ont fait l'objet de nombreux travaux. Les données concernant le lupin ont été revues récemment par Hill (1977), Vogt, Harnisch \& KRIEg (1979, a et b), Lacassagne (1979), Guillaume (1980). A condition d'être utilisé à un taux inférieur à 20 p. cent dans le régime et supplémenté avec de la DL-méthionine, le lupin bleu (L. angustifolius), peut se substituer aux sources classiques de protéines sans affecter les performances de croissance du poulet (Yule \& Mc Bride, 
1976). Il en est de même pour le lupin jaune (L-luteus) (SMetana \& Morris, 1972 ; Sourdshiska, Harnisch \& Vogt, 1977). La limite d'incorporation du lupin blanc (L-allis) est du même ordre de grandeur que pour les autres espèces (KORELESKi, Rys \& Kuchta, 1974). Mais en équilibrant le régime par des additions de DLméthionine et de L-lysine, HCL, LaCASSagne (1979) a montré que le lupin blanc (L-albus), variété «Kalina» peut être incorporé dans le régime alimentaire du poulet sans modifier ni le grain de poids, ni l'indice de consommation. Il faut cependant remarquer que dans cette expérience les régimes comportant du lupin sont distribués aux animaux entre 7 et 28 jours dâge. Selon Vogt, Harnisch \& Krieg (1979), la proportion de lupin dans l'aliment doit être modulée en fonction de l'âge du poulet : de $10 \mathrm{p}$. cent à la naissance jusqu'à $30 \mathrm{p}$. cent à la troisième semaine d'âge.

De la même façon que pour le lupin, la féverole (Vicia faba L.) et le pois (Pisum sativum) ne semblent pas diminuer les performances de croissance du poulet lorsqu'ils sont incorporés dans le régime à des taux variant de 10 à $15 \mathrm{p}$. cent (Guillaume, 1977). Dans le cas de la féverole, Kardivel \& Clandinin (1974) n'ont enregistré aucun effet dépressif sur la croissance du jeune poulet en utilisant la matière première à des taux inférieurs à $20 \mathrm{p}$. cent. Des résultats semblables sont obtenus avec des taux légèrement supérieurs, $25 \mathrm{p}$. cent (S IANNon \& Clandinin, 1977) et même 28 p. cent (M :QuARdT \& CAMPBeli, 1973).

L'emploi du pois dans l'alimentation du poulet a fait l'objet de plusieurs travaux récemment revus par VogT, HARnisch \& KRIEG (1979). D'une façon générale, les dépressions de croissance ne sont observées que lorsque le pois constitue la principale source de protéine et cela malgré la supplémentation avec de la DLméthionine (Kienholz, Jensen \& Mc Ginnis, 1962; Moran, Summers \& Jones, 1968 ; Goatcher \& Mc Ginnis, 1972). En revanche, Vogt, Harnisch \& Krieg (1979) ont montré que l'incorporation de $5,10,15,20,25,30$ et 35 p. cent de pois, dans des rations isoénergétiques et isoazotées granulées et équilibrées par des additions de DL-méthionine, n'exerce aucun effet défavorable sur la croissance et l'efficacité alimentaire.

Ces données bibliographiques laissent penser que l'emploi des quatre protéagineux à des taux relativement faibles : $5 \mathrm{p}$. cent pour le $\mathrm{PX}_{1}, 10$ à $15 \mathrm{p}$. cent pour le lupin, la féverole et le pois ne doit pas déprimer sensiblement les performances de croissance. Nos résultats montrent qu'il n'en est pas toujours ainsi lorsque ces protéagineux se trouvent associés dans la même ration. Il faut considérer d'une part l'âge auquel les aliments expérimentaux sont distribués, d'autre part la nature des protéagineux incorporés dans chaque aliment.

Les performances obtenues chez le poulet nourri depuis la naissance avec des régimes renfermant des protéagineux sont moins élevées que lorsque ces mêmes régimes sont distribués seulement pendant la période de finition. Tout se passe comme si le jeune poussin était plus sensible soit à des facteurs limitants (déficience ou indisponibilité partielle d'un nutriment indispensable), soit à des facteurs antinutritionnels présents dans le régime. Les facteurs limitants éventuels doivent être recherchés en dehors du groupe des trois acides aminés indispensables : méthionine, lysine et tryptophane. Dans notre expérience, tous les régimes sont bien pourvus en protéines totales (LARBIER \& DUPONT, 1980). Ils sont équilibrés par l'addition de DL-méthionine, L-lysine $\mathrm{HCl}$ et éventuellement de L-tryptophane. Certes, l'indisponibilité d'autres acides aminés peut être mise en cause. Pour améliorer la qualité des mauvais mélanges, il suffirait alors de pallier les déficiences. 
La baisse de performances observées avec les régimes comportant à la fois du pois et du concentré protéique de luzerne peut être due à la présence dans les deux matières premières de facteurs antinutritionnels identiques ou agissant en synergie et déprimant la consommation alimentaire.

Dans le pois (Pisum sativum) l'hemagglutinine (De Muelenaere, 1965; LieNER, 1974) ainsi que l'inhibiteur trypsique (VALDEBOUZE, 1977) sont en trop faible quantité pour expliquer à eux seuls les effets dépressifs observés. Dans le concentré protéique de luzerne, les facteurs antinutritionnels éventuels autres que les saponines ne sont pas encore connus.

En définitive, les résultats obtenus dans cet essai montrent qu'on peut envisager le remplacement total du tourteau de soja par des associations de protéagineux. Les combinaisons lupin-pois- $\mathrm{PX}_{1}$ et féverole-pois- $\mathrm{PX}_{1}$ ne peuvent pas être retenues tant que les facteurs préjudiciables n'ont pas été reconnus. Dans le cas des mélanges lupin-féverole-pois ou lupin-féverole- $\mathrm{PX}_{1}$ (la féverole étant pauvre en tanins), les résultats obtenus sont en revanche très honorables. Les associations de protéagineux ont donc un comportement original, elles n'additionnent ni toutes les qualités, ni tous les défauts de leurs composants; certaines étant préférables à d'autres, de nouvelles recherches s'avèrent nécessaires afin d'aboutir à de meilleures formulations.

Accepté pour publication en juin 1981.

\section{Summary \\ Replacement of soybean meal by meat meal and associations of protein plants in broiler diets}

A total of 1080 male broilers were raised to the age of 7 weeks and distributed into 9 groups. The control group was fed a starter diet (TD) (from 0 to 4 weeks) (table 2) and then a finishing diet (TF) (from 4 to 7 weeks) (table 3) containing maize-wheat and soybean meal. Four groups were fed from birth with diets in which the soybean meal was replaced by meat meal and an association of 3 protein plants out of the 4 studied : lupin (lupinus albus L.) field bean (Vicia faba L.), pea (Pisum Sativum L.) and a lucerne protein concentrate $\left(\mathrm{PX}_{1}\right)$. In addition, four groups received the starter diet (TD). and then one of the finishing diets including a combination of protein plants. The energy and essential amino acid contents of the experimental diets were the same as those of the controls.

The growth performance depended on the nature of the protein plants used and on the age at which the experimental diets were offered. Replacement of soybean meal by the protein plants both in the starter and in the finishing diets led to a lowering of weight gain and feed efficiency. On the other hand, use of diets including «lupin-field bean-pea 》 or «lupin-field bean-PX $X_{1}$, during the finishing period did not significantly affect the growth performance. However, the presence of peas and $\mathrm{PX}_{1}$ simultareously always reduced the weight gain and increased the feed conversion ratio.

\section{Références bibliographiques}

BLum J.C., 1980. Valeur alimentaire d'un concentrat de protéines extraites de la luzerne pour la production du broiler à peau jaune. 6th Europ. Poult. Conf. Hambourg, 3, 407-414.

Davidson J., 1980. Attempts to eliminate from field beans the anti-nutritive factor which reduces egg production. Br. Poult. Sci., 21, 299-307.

De Muelenaere H.J.H., 1965. Toxicity and haemagglutinating activity of legumes. Nature, 206, 4986, 827-828. 
Goatcher W.D., MC GinNIS J., 1972. Influence of beans, peas and lentils as dietary ingredients on the growth response of chicks to antibiotic and methionine supplementation of the diet. Poult. Sci., 51, 440-443.

Guillaume J., 1977. Use of field beans (Vicia faba L.) and peas (Pisum sativum) in laying-hen and growing chicken diets. Prot. Qual. Leg. Crops. Commission of the European Communities $c d$., EUR $5686 \mathrm{EN}, 217-235$.

Guillaume J., 1980. The nutritive value of lupins seed in farm animals. 1st Int. Lupine Workshop, Lima.

HiLL G.D., 1977. The composition and nutritive value of lupin seed. Nutr. Abst. Rev., Série B, 47, 511-529.

Kardivel R., Clandinin D.R., 1974. The effect of faba beans (Vicia faba L.) on the performance of turkey poults and broiler chicks from 0 to 4 weeks of age. Poult. Sci., 53, $1810-1816$.

KIEnHolz E.W., Jensen L.S., Mc GinnIS J., 1962. Evidence for chick growth inhibitors in several legume seeds. Poult. Sci., 41, 367-371.

Koreleski J., Rys R., KUChTa M., 1974. Seeds of field bean field peas and lupine as a major dietary protein source in broilers. Acta agrar. sylv. Zootech., 14, 57-70.

LaCASSAgne L., 1979. Valeur alimentaire du lupin blanc doux; Variété Kalina chez le Poussin en croissance. In : Matières premières et Alimentation des volailles, I.N.R.A., Station de Recherches Avicoles. Séance de travail des 18 et 19 octobre 1979, 43-56.

Larbier M., 1980 a. Valeur alimentaire du lupin doux (Lupinus albus L.) chez la poule pondeuse. Arch. Geflïgelk., 44, 224-228.

Larbier M., 1980 b. Utilisation de la féverole (Vicia faba L.) riche ou dépourvue de tanins dans l'alimentation de la Poule pondeuse. Arch. Geflügelk., 44, 163-167.

Larbier M., Dupont C., 1980. Réduction du taux protidique des aliments Poulet de chair et efficacité de la L-lysine, HCl. 6th Europ. Poult. Conf. Hambourg, 3, 264-271.

LeClerce B., Blum J.C., Boyer J.P., 1977. Signification and genetic control of body weight change in the hen during the laying period. Arch. Geflizgelk., 41, 121-124.

Liener I.E., 1974. Phytohemagglutinins : their nutritional significance. J. agr. Food Chem., $22(1), 17-22$.

Maquardt R.R., Campbell R.R., 1973. Raw and autoclaved faba beans in chick diets. Can. J. anim. Sci., 53, 741-746.

Moran E.T., Summers J.D., Jones G.E., 1968. Field peas as a major dietary protein source for the growing chick and laying hen with emphasis on high temperature steam pelleting as a practical mean of improving nutritional value. Can. J. anim. Sci., 48, 47-54.

Shannon D.W.F., Clandinin D.R., 1977. Effects of heat treatment on the nutritive value of faba beans (Vicia faba) for broiler chickens. Can. J anim. Sci., 57, 499-507.

Smetana P., Morris R.H., 1972. Lupin seed meal in broiler rations. Proc. Austr. Poultry Sci. Conf., Auckland, 209-217.

Sourdshisska S., Harnisch S., Vogt H., 1977. Sweet lupin meal in broiler feeding. Prot. Qual. Leg. Crops, Commission of the European Communities ed., EUR 5686 EN, 290-292.

Truchetro M., 1977. L'utilisation des protéines extraites de la luzerne. Bull. Inf. Ind. Alim. Anim., 12, 23-26.

VAldebouze P., 1977. Trypsin inhibiting and hemaegglutinating activities in seeds of some legume species. Prot. Qual. Leg. Crops., Commission of the European Communities ed., EUR 5686 EN, 87-98.

Vogt H., Harnisch S., Krieg R., 1979a. Der Einsatz von Süsslupinenschrot im Geflügelfutter. Arch. Gefliugelk., 43, 229-238.

Vogt H., Harnisch S., Krieg R., 1979b. Der Einsatz von erbsenschrot im Geflügelfutter. Arch. Geflügelk., 43, 195-199.

YULE W.J., MC BRIDE R.L., 1976. Lupin and rapeseed meals in poultry diets : effect on broiler performance and sensory evaluation of carcasses. Br. Poult. Sci., 17, 231-239. 